\title{
Lactobacilli Enjoyed Fermented Herbs on to the Last Fragment and Regulated Leucocyte Subsets and Anti-Oxidative Activity
}

\author{
Nobuo Yamaguchi ${ }^{*}$, Yoshiichiroh Mastuba1, Kazuhiro Okamoto², Daisuke Sakamoto³, \\ Takanao Ueyama ${ }^{4}$, Hideo Matsuno ${ }^{5}$, Nurmuhamamt Amat ${ }^{6}$
}

${ }^{1}$ Ishikawa Natural Medicinal Products Research Center, Ishikawa, Japan

${ }^{2}$ Department of Rehabilitation, Kanazawa Medical University, Uchinada-Machi, Japan

${ }^{3}$ Department of Heart Surgery, Kanazawa Medical University, Himi Municipal Hospital, Himi, Japan

${ }^{4}$ Department of $2^{\text {nd }}$ Internal Medicine, Kansai Medical University, Osaka, Japan

${ }^{5}$ Department of Otolaryngology, Kanazawa Medical University, Uchinada-Machi, Japan

${ }^{6}$ Traditional Uighur Medicine Department, Xinjiang Medical University, Urumqi, China

Email: *serumaya@kanazawa-med.ac.jp

How to cite this paper: Yamaguchi, N., Mastuba, Y., Okamoto, K., Sakamoto, D., Ueyama, T., Matsuno, H. and Amat, N. (2017) Lactobacilli Enjoyed Fermented Herbs on to the Last Fragment and Regulated Leucocyte Subsets and Anti-Oxidative Activity. Open Journal of Rheumatology and Autoimmune Diseases, 7, 30-45. https://doi.org/10.4236/ojra.2017.71003

Received: February 3, 2016

Accepted: January 3, 2017

Published: January 6, 2017

Copyright $\odot 2017$ by authors and Scientific Research Publishing Inc. This work is licensed under the Creative Commons Attribution International License (CC BY 4.0).

http://creativecommons.org/licenses/by/4.0/

\begin{abstract}
Eighty sorts of herbs were fermented by Lactobaccilli $(f-E S H)$. This material was proved by as safe in animal safety experiment. This work was aimed to revise the traditional way of hot water extraction to the fermentation, in order to use up the original material and searching new activity as well. We tried to prove the new activity by fermentation for immune-competent cells in the host that administrated both of original remedy and the new fermented sample. In rodents, immune-compromised host was prepared with cancer chemotherapeutic agent. Our observations showed that the antigen stimulated animal increased the antibody producing cell for heterologous erythrocyte by compromizedhost by $f-E S H$. Moreover, by administration of $f-E S H$ to immnosuppressed hosts, these samples regulated lymphocyte in number and functions, macrophage activities, and regulating anti-oxidative activity by phagocytic cells. The anti-oxidative assay was carried out ex-vivo system by peritoneal excaudate cell that we propose as suitable system for evaluating antioxidative assay. With these evidences, the original COF only augmented the level of lymphocytes in number, while $f-E S H$ regulated the ratio of granulocytes and lymphocyte. In clinical study with 20 healthy volunteers, granulocyte and lymphocyte ratio was also resulted as neutral in peripheral white blood cells, 1, 2 and 3 weeks after the administration of $f-E S H$. We discussed the significance and mechanism of cleving complement components $\mathrm{Fb}$ by $f-E S H$ in this text. $\mathrm{Fb}$. The new cleavage of complement was directly evident by immune-electrophoretic method. In conclusion, this modification of food
\end{abstract}


materials introduced new style of food intake resulted in the significant regulation such as antibody producing cells and anti-oxidative activity for phagocytic cells comparing traditional processing by hot water extraction.

\section{Keywords}

Wild Herbs, Fermentation, Lactobacilli, Lymphocyte, Granulocyte, Ant-Oxidative Activity, GABA, Complement, Alternative Complement Activation

\section{Introduction}

About our defense system, the overwhelming problems of developing our dual system, the innate and inductive do not seem to guard or even prevent the development of one internal threat to survival. Moreover, every individual exposes to the risk of immunodeficiency in daily life with both internal and externals factors. Complementary and alternative medicines (CAM) have achieved more and more attentions since they are able to cure many chronic illnesses, such as fatigue syndrome that plagues the developed world. The present study had concerned that typical styles of CAM, preparing special molecule for both digestive and easy to activated human complement component that regulate functions of leukocytes in human as well as animal immune system [1]-[7]. Dietary and fermented formula held promise as strong inducers of augmentation of acquired immunity. While the immune system is working against the local infection of pathogens, cytokine and immuno-competent cells react throughout the whole physical system in close connection to the brain, the endocrine and immune system [1] [2] [3] [4] [5]. In this report, we hypothesized that $\boldsymbol{f}$-ESH might influence immuno-competent cells qualitatively and quantitatively $f-E S H$ targeting lymphocytes based on the constitution dependent manner. COF had been employed as tonic agent and the implication has little been made on the characteristics of the levels of leukocyte subset, such as granulocytes and lymphocytes, metabolic disorder such as diabetes mellitus, malnutrition, extreme exhaustion, stress, aging and medical side effect in cancer [6] [7] [8] [9] [10]. So we have to select appropriate menu to regulate immune function through leukocyte storage. The menu has been summarized and listed as CAM: complementary and alternative medicine.

In this study, we tried to focus on the identity of $\boldsymbol{f}$ - $E S H$ formula, comparing to another non-fermented decoction. The hot water extraction was traditionally succeeded to the present, wasting almost all the original material was discarded after use. With a series of trial, we tried to process the original material into small fragment by microbe and to find new molecule to affect our physical system as well as use up of the material for global sense of ecological system. The influence of $\boldsymbol{f}-\boldsymbol{E S H}$ on leukocyte and/or lymphocyte subpopulations in human peripheral blood was also discussed. One of the main purposes of this work was 
to revise the traditional way for preparation of remedy, from hot-water extraction to fermentation in order to use up the original material and searching new activity beside of hot water extraction. For the preparation of TCM remedy, it was succeeded as hot water extraction, wasting the almost all the original material as that of many tea extraction/preparation in all over the world. Moreover, some preliminary trial that concerned the new processing of the original material by degradation by acidophilic bacteria, fermentation.

\section{Materials and Methods}

\subsection{Preparation of Wild Herbs and Fermented Herbs}

Commercially available 80 sorts of wild herbs were prepared and extracted by $100 \mathrm{ml}$ of hot water (98C) to $10 \mathrm{gr}$ of grained roasted material. For 3 minutes. On the other hand, the fermentation was carried out by Lactobacillus leuteria for 5 days at $40 \mathrm{C}$, and was repeated two times in the method described in M \& M. After the centrifugation of $2000 \times \mathrm{g}$ for $10 \mathrm{~min}$ at room temperature and then, dried by heating as powder and served for $f-E S H$.

\subsection{Fermentation and GABA Generation}

Commercially available 80 sorts of wild herbs were prepared and extracted by $100 \mathrm{ml}$ of hot water (98C) to $10 \mathrm{gr}$ grained the roasted material. for 3 minutes. The fermentation was carried out by Lactobacillus leuteria for 5 days at 40C. Each ratio of powdered, lactobacilli and water was 100:50:850, prepared by ECHIGO YAKUSOU, Ltd. Niigata, Japan). After the centrifugation of $2000 \mathrm{xg}$ for $10 \mathrm{~min}$ in a room temperature and supernatant was served for $\boldsymbol{f}$-ESH. GABA: gamma amino acid butyric acid was evaluated by the test system [11] [12].

Followings were the method for quantifying $\gamma$-aminobutyric acid, which comprises the steps of producing reduced nicotinamide adenine di-nucleotide phosphate by using a specific aminotransferase and a dehydrogenase that needs to use oxidized nicotinamide adenine di-nucleotide phosphate as a coenzyme and deactivating the enzymes, thereby removing any amino acid having a similar structure to that of GABA and acting an electron carrier on NADPH produced in the aforementioned step in the presence of a tetrazolium salt that can produce a water-soluble formazan dye and measuring the water-soluble formazan dye described and reported in references [11] [12].

\section{Animal Experiment}

\subsection{Single and Multiple Dose Toxicity}

Seven-week-old ddY mice consisted with 7 individuals $(21 \pm 1.5 \mathrm{gr})$ were used for the acute oral toxicity study. The tests were carried out according to Ethics of the Organization for Economic Co-operation and Development (OECD) Test Guideline 401 . The mice were kept at animal room, $24^{\circ} \mathrm{C} \pm 1{ }^{\circ} \mathrm{C}, 50 \%$ relative humidity. The selection of female mice was due to their gentle behavior in the 
animal cage. Both conventional and fermented coffee were suspended in sterile and administered to $100 \mathrm{mg} /$ day via stomach tube. Another food and water supply were freely administered. Mice were weighted at 0 - 7 days after administration, and clinical observations were made once a day. Necropsy was performed on all mice seven days after administration.

\subsection{Animals Experiment for Preclinical Trial}

Eight week-old female SPF C57BL/6 were purchased from Sankyo Laboratory Service Corporation (Shizuoka, Japan). All mice were kept under specific pathogen-free conditions. Mice food and distilled water were freely accessible for each mouse. Housing temperature and humidity were controlled $25^{\circ} \mathrm{C} \pm 1^{\circ} \mathrm{C}$ and $60 \%$.

\subsection{Reagents and Preparation}

About the fundamental medium for anti-oxidative activity, HEPES buffer (HEPES 17 mM, NaCl 120 mM, Glucose 5 mM, KCl 5 mM, $\mathrm{CaCl}_{2} 1 \mathrm{mM}, \mathrm{MgCl}_{2}$ $1 \mathrm{mM}$ ) was prepared and sterilized by filtration. Phorbol 12-myristate 13-acetate (PMA, Sigma, USA) was diluted to $10^{-6} \mathrm{M}$ by dimethyl sulfoxide DMSO, Sigma, USA) and used as a stimulant for super oxide anion generation for mouse peritoneal exudates cells. Cytochrome-C (Sigma, USA) was diluted to $1 \mathrm{mM}$ by HEPES buffer. Since cytochrome-C reduced by super oxide showed maximum absorbance at $550 \mathrm{~nm}$, we used cytochrome-c to measure the amount of super oxide anion generation through spectro-photometrical technique. Oyster Glycogen (type II, Sigma, USA) was diluted in the purified water $(10 \% \mathrm{w} / \mathrm{v}$, Wako, Japan) and autoclaved at $120^{\circ} \mathrm{C}$ for $20 \mathrm{~min}$. This solution was used for intraperitoneal injection to mice in order to induce peripheral neutrophils into the abdominal cavity (Figure 1).

<Preparation of murine peritoneal exudative cells>
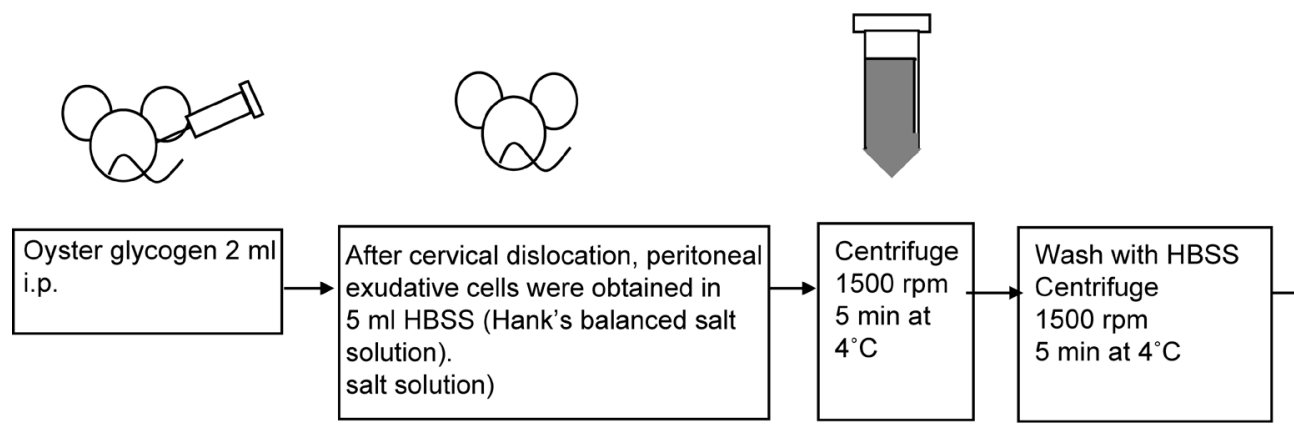

Wash with HEPES buff.

Centrifuge

$1500 \mathrm{rpm}$

5 min at $4^{\circ} \mathrm{C}$

$<$ Measurement of generated super oxide $>$

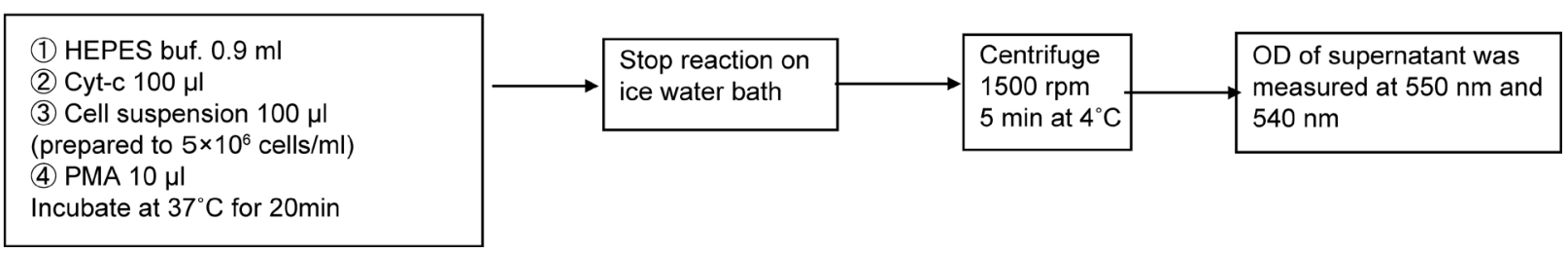

Figure 1. Experimental procedure for accessing Anti-oxidative activity of the murine Macrophage. 


\subsection{Assessing the Amount of Super Oxide Anion Generated by Mouse Macrophage}

Each sample was orally inoculated to mice $(500 \mathrm{mg} / \mathrm{kg}$ ) for one week. Two milliliters of $10 \%$ Oyster glycogen was injected intraperitoneally 10 hours before the assay. Sufficient murine peritoneal exudative cells were collected ten hours after the stimulation. Mice were euthanized by cervical dislocation, murine peritoneal exudates cells (PEC) suspension was centrifuged twice for 5 minutes at $1500 \mathrm{rpm}$ at $4^{\circ} \mathrm{C}$. Then PEC was prepared to $1 \times 10^{6} \mathrm{cells} / \mathrm{ml}$ of HEPES buffer. One hundred microliters of cytochrome-c and $10 \mu \mathrm{l}$ of PMA were added to the cell suspension and this was incubated for 20 minutes at $37^{\circ} \mathrm{C}$. The reaction mixture was then centrifuged for 10 minutes at $1500 \mathrm{rpm}, 4^{\circ} \mathrm{C}$. An optical density of supernatant was measured at both $550 \mathrm{~nm}$ and $540 \mathrm{~nm}$, the amount of generated super oxide anion was estimated in the formula; increased absorbance at $550 \mathrm{~nm}$ $\left(\Delta \mathrm{A}_{550-540}\right) / 19.1 \times 10^{3}(\mathrm{mmol} / \mathrm{ml})$. In order to ensure if we really measured the amount of generated super oxide anion or not, we tried to add super oxide anion dismutase (SOD), an enzyme for its anti-oxidative effect, into our experimental system. The result was as expected that the reduction of cytochrome-c was suppressed after the addition of SOD. This showed us that our experimental system could be used properly for measuring the amount of generated super oxide anion inside the cytoplasm of phagocytic cells.

\subsection{Statistical Analysis}

Data are expressed as means \pm standard deviations. The differences between COF-treated and non-treated conditions were compared using a one-tailed analysis of variance. A $P$ value $<0.05$ was regard to be statistically significant.

\section{Results}

\subsection{Animal Test for Fermented ESH}

\subsubsection{Single and Multiple Dose Toxicity Study for Conv. ESH and f-ESH}

Seven female seven-week-old ddY mice, were used for the acute oral toxicity study. Mice were weighted at $0-7$ days after administration, and clinical observations were made once a day. Necropsy evaluation of the mice did not reveal any significant differences in thymus, liver, spleen, kidney, adrenal gland and testicle weights between the control group and both conventional water and charged and activated water.

\subsubsection{Amount of Generated Super Oxide Anion Regulated by $f$-ESH}

The amount of generated super oxide anion was calculated in the formula shown above. The generated super oxide anion after one week administration of heat extracted coffee and fermented coffee were 2.3 and $1.6 \times 10^{-5} \mathrm{mmol} / \mathrm{ml}$, respectively, whereas that was $2.8 \times 10^{-5} \mathrm{mmol} / \mathrm{ml}$ in control group. All these samples, regulated heat extracted COF showed anti-oxidative activity to the control group $(\mathrm{P}<0.05)$ and fermented one showed more significant $(\mathrm{P}<0.01)$, decreased super oxide anion generation after administration for one week in mice (Figure 2). 


\section{Clinical Findings}

\subsection{Changes in Cell Number of Total Leukocyte and Subsets by Conv ESH \& $f$-ESH}

Leukocyte numbers have been counted one hour before and 15 days after the treatment of-ESH derivatives. The cell number measured one hour before the administration was set as $100 \%$. Relative percentage of cell number on the 15th day was calculated. No significant changes were observed in G-group after the administration of-ESH. However, significant change was found in L-type group (Table 1).

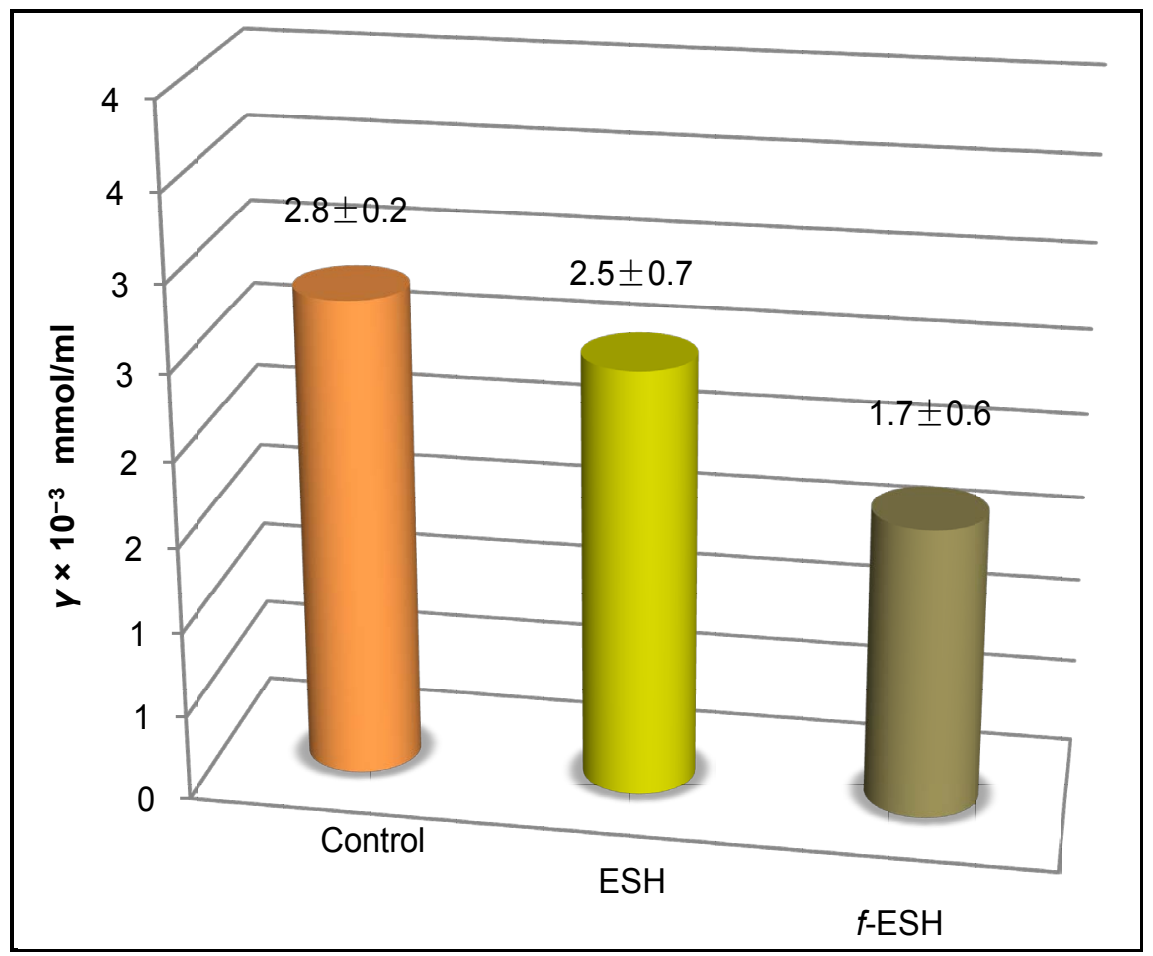

Figure 2. Anti-oxidative activity by fermented coffee and conventional heat-extracted one.

Table 1. Constitution dependent regulation of leukocyte by COF derivatives.

\begin{tabular}{ccccc} 
& \multicolumn{2}{c}{ G type individual } & \multicolumn{2}{c}{ L type individual } \\
\cline { 2 - 5 } & \multicolumn{2}{c}{$f-E S H$} & \multicolumn{2}{c}{$f-E S H$} \\
\cline { 2 - 5 } & Before & After & Before & After \\
\hline Total WBC $\left(\times 10^{3} \mu \mathrm{l}\right)$ & 6.36 & 5.88 & 4.89 & 5.66 \\
Lymphocyte (\%) & 25.8 & 32.6 & 44.7 & 36.8 \\
Granulocyte (\%) & 68.4 & 66.3 & 54.8 & 61.3 \\
Neutrophil (\%) & 63.5 & 52.6 & 42.6 & 57.3 \\
Eosinophil (\%) & 1.7 & 2.3 & 2.5 & 3.5 \\
Basophil (\%) & 0.7 & 0.8 & 0.6 & 0.7 \\
\hline
\end{tabular}




\subsection{Dividing Subjects into Two Groups, G-Type and L-Type by Granulocyte and Lymphocyte Proportion}

The volunteers were healthy subject, with no drastic change for the total number of leukocytes. However, we tried to check the regulative effect of herbal formulae for two different constitution, G-rich type and L-rich type. Analysis that mixed both groups together showed no significant differences in total leukocyte number except that for $f$-ESH; in G-type group, total number of leukocytes was down regulated by $\boldsymbol{f}-E S H$. This was a result of the down regulation of major group of leukocyte, granulocyte (Table 2).

As for the G-type, no significant changes were found after the treatment of both COFs. In the L-type group, $f-E S H$, on the other hand, increased the tonal leukocyte and granulocyte in number, on the contrary to the down regulation for lymphocytes. To further clarify the influence of hemopoietic formula, we divided the subjects into two groups: the G type group, who had a granulocyte count over $60 \%$, and the L type group, who had a lymphocyte count over $40 \%$. In the L type group, lymphocyte counts tended to decrease on day 15, accompanied by an increase in granulocyte numbers by conventional coffee but not by COF. On the contrary, the granulocyte counts of G type group tended to decrease on day 15. The decrease of granulocyte count was raised by fermented Coffee, but not by conventional Coffee on day 7 .

\subsection{The Complement System; Another Stage for Focusing by Fragmented Polysaccharide by $f$-ESH}

It was possible to focus on another important factor of immunological component, complement either classical and/or alternative pathway. These proteins are composes of at least 9 components. These proteins are famous for its acute arrangement against infections organisms as in the defense immunity. However, we had found that the complement had worked when we introduced fragmented/fermented polysaccharide as complement activator, so called alternative

Table 2. Constitution dependent regulation of lymphocyte by FSH derivatives.

\begin{tabular}{ccccc}
\hline & \multicolumn{2}{c}{ G type individual } & \multicolumn{2}{c}{ L type individual } \\
\cline { 2 - 5 } CD & \multicolumn{2}{c}{$f$-ESH } & \multicolumn{2}{c}{$f$-ESH } \\
\cline { 2 - 5 } & Before (\%) & After (\%) & Before (\%) & After (\%) \\
\hline CD2 & 64.6 & 71.7 & 62.43 & 61.84 \\
CD4 & 18.44 & 29.64 & 31.65 & 30.678 \\
CD8 & 37.86 & 43.65 & 26.77 & 27.98 \\
CD11 & 73.89 & 66.75 & 62.75 & 69.54 \\
CD14 & 0.04 & 0.07 & 0.06 & 0.08 \\
CD16 & 67.55 & 59.86 & 54.24 & 47.64 \\
CD19 & 8.77 & 8.98 & 8.66 & 7.88 \\
CD56 & 1.34 & 1.46 & 1.48 & 2.79 \\
\hline
\end{tabular}


pathway conjunct to Alternative Medicine. So in this chapter, we would like to show the nature of complement and activated mechanism that lead to the activation of all the physical activities through the augmentation of complement receptor positive structure cells. Activation of the complement system results in a cascade of interactions of these proteins, leading to the generation of products that have important biologic activities and that constitute an important humoral mediator system involved in inflammatory reactions. First, coating of particles, such as bacteria or immune complexes, with certain components of complement facilitates the ingestion of the particle by phagocytic cells (opsonic function of complement). Second, the activation event generates many fission products of complement proteins for which specific receptors exist on a variety of inflammatory cells, such as granulocytes, lymphocytes, and other cells. Binding of these complement-derived products to such receptors results in biologic activities such as chemotaxis and hormone-like activation of cellular functions, inflammatory function of complement [15] [16] (Figure 3).

\subsection{Pathways of Complement Activation and Complement Proteins by $f$-ESH}

The complement elements can activate by two pathways: the classical and the alternative pathways. Both pathways lead to a common terminal channel correspond to as the pathway of membrane attack complex. Twenty plasma proteins, are now known to be constituents of these pathways. These proteins can be divided into functional proteins, which represent the elements of the various pathways, and regulatory proteins, which exhibit each function. The blood level of the proteins in normal human varies a broad range. They are synthesized in the liver but also by cells of the lympho-reticular system, such as lymphocytes and monocytes. Both the classical and the alternative complement pathways can be organized into various operational units: initiation, amplification, and membrane

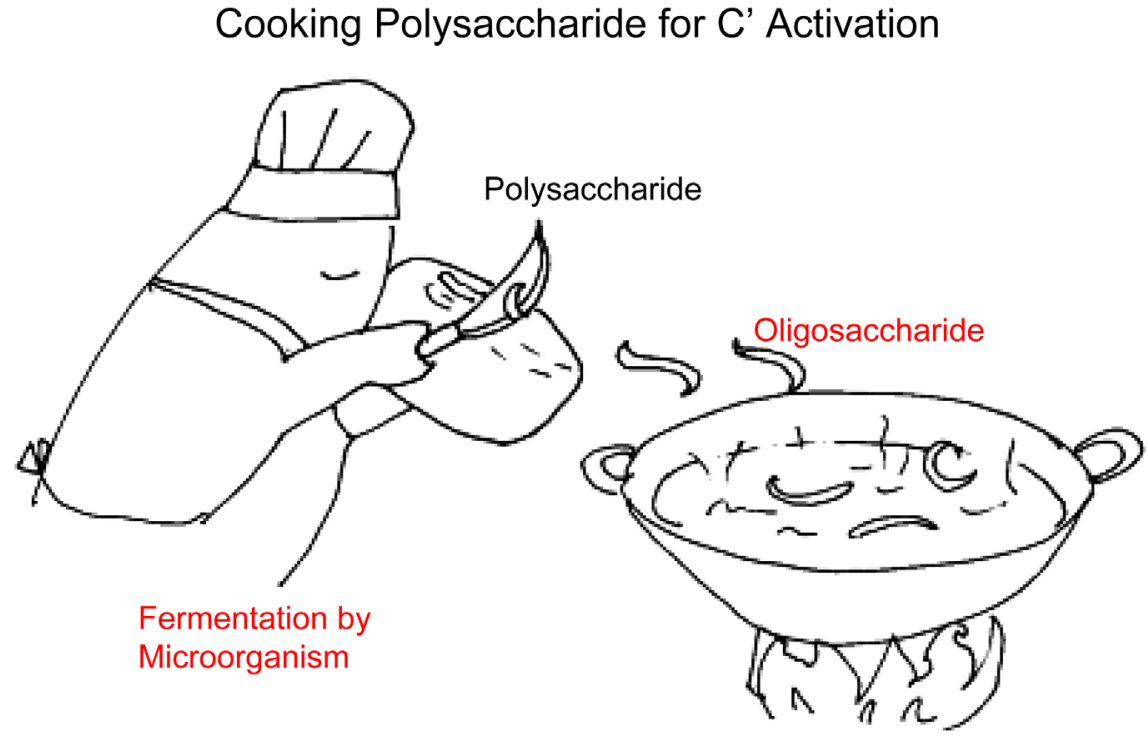

Figure 3. Illustrative imaging for degradation of polysaccharide by microorganism. 
attack. Following an initial recognition event, which leads to initiation of the pathway, an amplification phase takes place that involves the action of proteases and the recruitment of additional molecules; this is followed by a terminal phase of membrane attack during which the cell dies. The recognition unit for the classical pathway, C1, is composed of three separate proteins, Clq, Clr, and Cls. The initiation of this pathway of complement typically involves the reaction of antibody with antigen, which may be soluble or on the surface of a target cell. This antigen-antibody reaction allows the binding of Clq to two or more $\mathrm{Fc}$ regions of certain IgG subclasses (IgG1, IgG2, IgG,) or Ig activators of the classical pathway. The ultra structure of Clq has been demonstrated by electron microscopy to consist of six subunits similar to a bouquet of six flowers. The central stalks of Clq resemble collagen in primary and secondary structure. Upon binding of one Clq molecule to the $\mathrm{Fc}$ regions of two or more antigen-bound antibody molecules, CIr proenzymes are activated. The chemical basis of this activation is the cleavage of a peptide bond by an autocatalytic mechanism, leading to the formation of activated $\mathrm{Clr}$, a protease that subsequently cleaves the proenzyme Cls. Thus, the binding of Clq to an immunoglobulin in complex with the antigen represents the recognition event of the classical pathway, resulting in the activation of Clr and Cls. The final result is the generation of an enzymatically active component, Cls, which will cleave and thereby activate the next proteins in the cascade, leading to amplification of the recognition event. The other activation process, polysaccharide molecule also hits the complement component. Therefore, some polysaccharide molecule hit the complement component in the manner of alternative pathway. Thus, U-164 derivatives activated human complement component and shown by immune elecrophoretic methods.

The enzymatic protein Cls has two physiologic substrates, C4 and C2. C4 is cleaved by $\mathrm{Cls}$ into $\mathrm{C} 4 \mathrm{a}$, one of the three anaphylatoxins (molecules that promote increased vascular permeability and smooth muscle contraction), and C4b, which binds to the target cell surface. Cls also cleaves $\mathrm{C} 2$ when $\mathrm{C} 2$ is in complex with $\mathrm{C} 4 \mathrm{~b}$. Cleavage of $\mathrm{C} 2$ generates $\mathrm{C} 2 \mathrm{~b}$, which is released, and $\mathrm{C} 2 \mathrm{a}$, which remains bound to C4b. The bimolecular complex C4b, $2 \mathrm{a}$ is a protease that cleaves C 3 and therefore is called C 3 convertase. Cleavage of C 3 by the C 3 convertase generates two important biologically active peptides, C3a (another anaphylatoxin) and cab, which attaches to target cell surfaces and can bind to C5. C5, when in complex with $\mathrm{C} 3 \mathrm{~b}$, can be cleaved by the $\mathrm{C} 3$ convertase (then referred to as $\mathrm{C} 5$ convertase). The $\mathrm{C} 5$ convertase hydrolyzes $\mathrm{C} 5$, which generates the $\mathrm{C} 5 \mathrm{a}$ anaphylatoxin and $\mathrm{C} 5 \mathrm{~b}$. C $5 \mathrm{~b}$ is the nucleus for the formation of the membrane attack complex. Immediately following their generation, $\mathrm{C} 3 \mathrm{~b}$ and $\mathrm{C} 4 \mathrm{~b}$ exhibit a unique transient ability to covalently bind to marked cells ("metastable binding site"). This property has reentry been shown to be due to an intramolecular thioester bond that is present between the sulfhydryl group of a cysteine residue and the gamma-carbonyl group of a glutamine residue on C3 and C4. Upon activation of $\mathrm{C} 3$ or $\mathrm{C} 4$, this thioester becomes highly reactive and can react with a cell surface hydroxyl or amino group. This results in the covalent attachment of 
$\mathrm{C} 3 \mathrm{~b}$ or $\mathrm{C} 4 \mathrm{~b}$ to the target cell. An additional function of the thioester bond is its hydrolysis by water, occurring during activation of the alternative pathway as described below.

The alternative pathway can be activated when a molecule of $\mathrm{C} 3 \mathrm{~b}$ is bound to a target cell. This $\mathrm{C} 3 \mathrm{~b}$ molecule combines with the plasma protein Factor $\mathrm{B}$, which is a zymogen, and which, when bound to $\mathrm{C} 3 \mathrm{~b}$, can be activated by the plasma protein Factor $\mathrm{D}$ by cleavage into two fragments, $\mathrm{Ba}$ and $\mathrm{Bb}$. The $\mathrm{Bb}$ fragment, which contains the active enzymatic site, remains bound to $\mathrm{C} 3 \mathrm{~b}$, as $\mathrm{C} 3 \mathrm{~b}, \mathrm{Bb}$. This complex, like C4b, 2a in the classical pathway, is a C3 convertase $(\mathrm{C} 3 \mathrm{~b} ; \mathrm{Bb})$; it is stabilized by the binding of another plasma protein, properdin. Thus, the alternative pathway used to be called the properdin pathway. The presence of a single molecule of $\mathrm{C} 3 \mathrm{~b}$ generates many molecules of $\mathrm{C} 3 \mathrm{~b}, \mathrm{Bb}$, resulting in a tremendous amplification. The $\mathrm{C} 3$ convertase $(\mathrm{C} 3 \mathrm{~b}, \mathrm{Bb})$ cleaves $\mathrm{C} 3$, thereby generating more molecules of $\mathrm{C} 3 \mathrm{~b}$, which can combine with other molecules of factor $\mathrm{B}$ to give more molecules of $\mathrm{cab}, \mathrm{Bb}$, which can, in turn, cleave more molecules of C3. Therefore, the central feature of the alternative pathway is a positive feedback loop that amplifies the original recognition event. As in the classical pathway, attachment of many $\mathrm{C} 3 \mathrm{~b}$ molecules to the target cell -will allow binding of $\mathrm{C} 5$ and its cleavage into $\mathrm{C} 5 \mathrm{a}$ and $\mathrm{C} 5 \mathrm{~b}$ by the enzyme $\mathrm{C} 3 \mathrm{~b}, \mathrm{Bb}$, now referred to as C5 convertase.

According to the potential of this positive feedback loop to rapidly use up Factor B and C3, the positive feedback must be carefully regulated. There are two important regulatory proteins in plasma. The start protein, Factor $\mathrm{H}$ (formerly referred to as $\mathrm{PIH}$ ), competes with Factor B for binding to $\mathrm{C} 3 \mathrm{~b}$ and also dissociates $\mathrm{C} 3 \mathrm{~b}, \mathrm{Bb}$ into $\mathrm{C} 3 \mathrm{~b}$ and $\mathrm{Bb}$. The second array protein, Factor I (formerly referred to as $\mathrm{C} 3 \mathrm{~b}$ in activator), cleaves $\mathrm{C} 3 \mathrm{~b}$ that is bound to Factor $\mathrm{H}$ or to a similar protein found on the surface of the host cell. The resulting cleaved $\mathrm{C} 3 \mathrm{~b}$, termed $\mathrm{iC} 3 \mathrm{~b}$, can no longer for C3 convertase. The action of these two control proteins prevents the consumption of Factor B and C3 in plasma; in addition, these two proteins in activate $\mathrm{C} 3 \mathrm{~b}, \mathrm{Bb}$ on host cell surfaces. In contrast, surfaces of many target cells, such as bacteria and other microorganisms, protect $\mathrm{C} 3 \mathrm{~b}, \mathrm{Bb}$ from in activation by Factors $\mathrm{H}$ and $\mathrm{I}$. This protection allows the positive feedback loop to proceed on the surface of the target cell, leading to the activation of the pathway and subsequent cell death. In other words, the alternative pathway is activated by those substances that prevent the inactivation of the positive feedback loop enzyme $\mathrm{C} 3 \mathrm{~b}, \mathrm{Bb}$. A substance is therefore treated as "foreign" if it limits the action of Factors $\mathrm{H}$ and I and allows the positive feedback loop to succeed.

The chemical structures on surfaces of particles and cells responsible for activation or non-activation of the alternative pathway have been identified [22]. There is some evidence that carbohydrate moieties are involved, particularly sialic acid. The alternative pathway protein(s) responsible for the recognition of these structures also remains to be determined. As pointed out earlier, the activation of the alternative pathway requires a $\mathrm{C} 3 \mathrm{~b}$ molecule bound to the surface 
of a target cell. An intriguing question is, "Where does the critical first cab molecule come from?" Although it can be provided by the $\mathrm{C} 3$ convertase of the classical pathway or by cleavage of $\mathrm{C} 3$ by plasmin and certain bacterial and other cellular proteases, the alternative pathway can generate this first C3b molecule without these proteases. The intramolecular thioester, which is highly reactive in nascent $\mathrm{C} 3 \mathrm{~b}$ and is responsible for the covalent attachment to targets, is also accessible in native C3 to water molecules. Thus, spontaneous hydrolysis of the thioester bond occurs constantly in plasma at a low rate. The C3 molecules in which the thioester bond has been hydrolyzed behave like C3b, although the C3a domain has not been removed. C3 with a hydrolyzed thioester is called C3 or C3b-like C3. It can bind Factor B and allow Factor D to activated Factor B, which results in formation of a fluid-phase $\mathrm{C} 3$ convertase, $\mathrm{C} 3, \mathrm{Bb}$. This enzyme is continuously formed and produces $\mathrm{c} 3 \mathrm{~b}$ molecules that can randomly attach to cells. Although these C3b molecules will be rapidly inactivated on host cells by Factors $\mathrm{H}$ and I, they will start the positive feedback loop on foreign surfaces, as outlined previously. In other words, the alternative pathway is constantly activated at a low rate, but amplification with subsequent cell death occurs only on foreign particles [17].

With this concept, we tried to demonstrate directory by the immune-electrophoresis. The human serum was prepared after administrating f-Black Turmeric together with the sample with before fermentation. Immuno-electrophoresis was setting up for $90 \mathrm{~min}$, followed by incubating with anti-human whole serum and specific for $\mathrm{C} 3$ and $\mathrm{Bf}$ component. These specific anti complement component serum were kindly supplied by Dr Syunnosuke SAKAI, Cancer Research Institute of Kanazawa University, Japan (Figure 4).

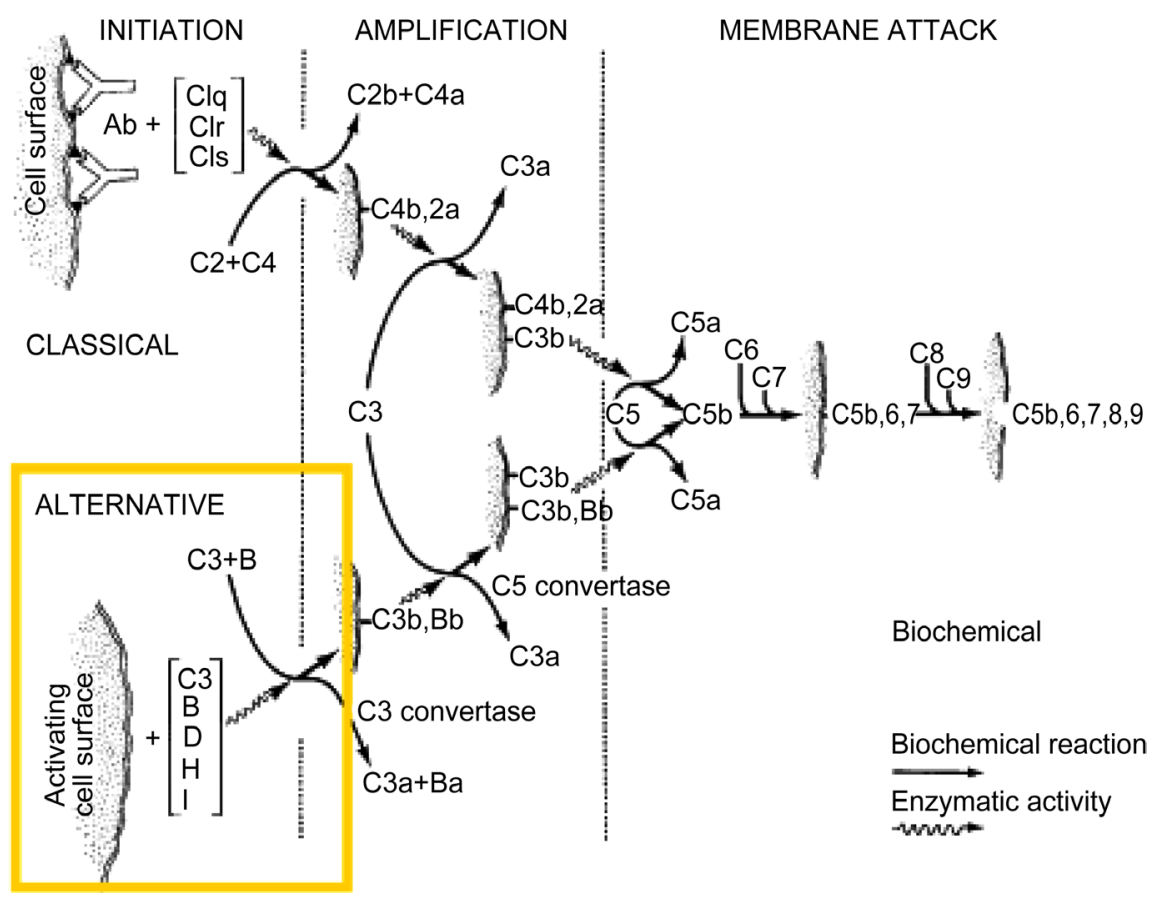

Figure 4. Diagrammatic representation of alternative complement component activation. 


\subsection{Direct Evidence of Complement Products Activation by $f$-ESH and Translation of Biological Activity}

Activation of either the alternative or the classical pathway results in the generation of many key peptides involved in inflammatory condition. The anaphylaxis increase of vascular permeability degranulation of mast cells and basophils with release of histamine Degranulation of eosinophils Aggregation of platelets opsonization of particles and solubilization of immune complexes with subsequent facilitation of phagocytosis Release of neutrophils from bone marrow resulting in leukocytosis Smooth muscle contraction Increase of vascular permeability Smooth muscle contraction Increase of vascular permeability modification of mast cells and basophils with release of histamine degranulation of eosinophils Aggregation of platelets Chemotaxis of basophils, eosinophils, neutrophils, and monocytes Release of hydrolytic enzymes from neutrophils Chemotaxis of neutrophils Release of hydrolytic enzymes from neutrophils Inhibition of migration and undulation of spreading of monocytes and anaphylatoxins $\mathrm{C} 3 \mathrm{a}, \mathrm{C} 4 \mathrm{a}$, and C5a are derived from the enzymatic cleavage of C3, C4, and C5 respectively. $\mathrm{Hi}$ storically, C3a and C5a were defined as factors derived from activated serum possessing spasmogenic activity. The anaphylatoxins are now recognized as having many additional biologic functions. Both $\mathrm{C} 3 \mathrm{a}$ and $\mathrm{C} 5 \mathrm{a}$ are known to induce the release of histamine from mast cells and basophils. As shown in the Figure anaphylatoxins cause smooth muscle contraction and induce the release of vasoactive amines, which cause an increase in vascular permeability. The effect of C5a anaphylatoxin on neutrophils is of considerable importance in the inflammatory response. Not only can C5a induce neutrophil aggregation, but this anaphylatoxin appears to be the main chemotactic peptide generated by activation of either complement pathway. In vitro, nano-molar concentrations of C5a will induce the unidirectional movement of neutrophils. Other inflammatory cells, such as monocytes, eosinophils, basophils, and macrophages, have also been shown to exhibit a chemotactic response to $\mathrm{C} 5 \mathrm{a}$. The removal of the carboxy-terminal arginine from $\mathrm{C} 5 \mathrm{a}$ by serum carboxyl peptidase $\mathrm{N}$, generating C5a-des-arg, inactivates the spasmogen, yet restoration of full chemotactic activity of C5a-des-are may occur in the presence of serum. Therefore, C5a-desarg may also be responsible for in vivo neutrophil chemotactic activity. As described earlier, the cleavage of $\mathrm{C} 3$ by either the alternative or the classical C3 convertases results in the production of two major split products, the $\mathrm{C} 3 \mathrm{a}$ anaphylatoxin and cab. The larger C3b fragment can serve as an opsonin (promoter of phagocytosis) by binding to a target through the thioester mechanism. This renders the particle or cell immediately susceptible to ingestion by a variety of phagocytic cells that carry specific receptors for $\mathrm{C} 3 \mathrm{~b}$. Many recent observations point to additional roles for complement fragments in regulating the activity 9 f cells of the immune system. These observations include the presence of receptors on lymphocytes for various complement proteins, including C3 split products and Factor $\mathrm{H}$, affecting $\mathrm{B}$ - and $\mathrm{T}$ cell function. This is an important area for future research [13]-[18] (Figure 5). 


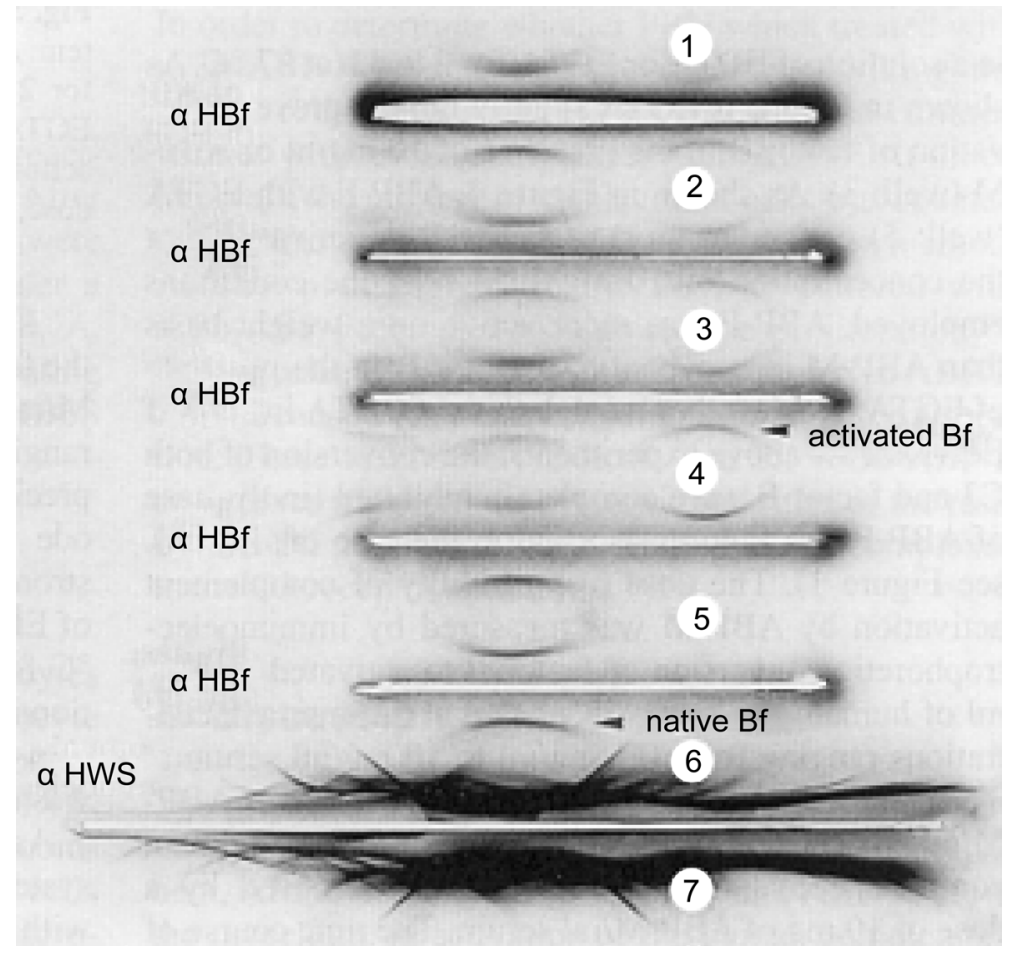

Figure 5. Immunoelectrophoretic demonstration of activated human complement components.

\section{Discussion}

We quantified CD positive cell counts as indicators of T cells, B cells, macrophages and NK cells. For qualitative and quantitative evaluation, we examined the cytokine expression levels, and directly measured the expression levels of cytokine-containing cells in peripheral blood, eliminating possible artificial factors that could arise from culturing in test tubes or changes in net value by catalyzation. To avoid any possible influence from the circadian rhythm, we obtained the whole blood from all donors at the same time. We reported that about hot-spring hydrotherapy and acupuncture, and had proposed that immune system regulation is an important factor for evaluating CAM. A possible explanation for immune enhancement could be the activation of the circular system and/or autonomic nervous system, although the details of the mechanism remain unclear. Further research regarding to the mechanism is necessary. The excitation of the sympathetic nervous system while lymphocyte count is increased by excitation of parasympathetic nervous system [19]-[25]. Our data also showed that granulocyte count was decreased in subjects with a high granulocyte count, while lymphocyte count was increased in the same subjects. The lymphocyte count, however, was decreased in subjects with a high lymphocyte level, while granulocyte count was increase in the same subjects. In other words, the subjects dominated FSH the sympathetic nerve could release stress, whereas the sympathetic activity of subjects who were dominated FSH. The parasympathetic nerve might be excited by hemopoietic formula. This way, the cell counts appeared to converge at appropriate levels after hemopoietic formula. Finally, in 
order to determine whether the elevation of leukocyte counts resulted from an infection triggered by hemopoitic formula or not, the subjects were followed up for 8 days after the last administration of hemopoitic formula. During that period, we could not observe any infectious signs such as pyodermitis, fever, or enhancement of C-reactive protein (CRP). The value of CRP was $0.57 \mathrm{~g} / \mathrm{dl}$ to $1.23 \mathrm{~g} / \mathrm{dl}$ in our subjects, suggesting very mild inflammatory responses, which showed that hemophilic formula did not cause infection. Since the meridian may influence cells throughout the body and may pass through every organ system, hemophilic formula stimulation might provide maximum benefits without side effects [26]-[29]. As an immune-enhancer, hemophilic formula merits further investigation as a possible treatment for acquired immunodeficiency syndrome, chronic fatigue syndrome.

\section{References}

[1] Yamaguchi, N., Arai, M. and Murayama, T. (2015) Aspect of QOL Assessment and Proposed New Scale for Evaluation. Open Journal of Immunology, 5, 147-182. https://doi.org/10.4236/oji.2015.53014

[2] Yamaguchi, N., Takahashi, T., Sugita, T., Ichikawa, K., Sakaihara, S., Kanda, T., Arai, M. and Kawakita, K. (2007) Acupuncture Regulates Leukocyte Subpopulations in Human Peripheral Blood. eCAM, 4, 447-453.

[3] Suzuki, S., Toyabe, S., Moroda, T., Tada, T., Tsukahara, A. and Iiai, T. (1997) Circadian Rhythm of Leukocytes and Lymphocytes Subsets and Its Possible Correlation with the Function of the Autonomic Nervous System. Clinical Experimental Immunology, 110, 500-508. https://doi.org/10.1046/j.1365-2249.1997.4411460.x

[4] Kitada, Y., Wan, W., Matsui, K., Shimizu, S. and Yamaguchi, N. (2000) Regulation of Peripheral White Blood Cells in Numbers and Functions through Hot-Spring Bathing during a Short Term-Studies in Control Experiments. Journal of Japanese Society Balneology Climatology Physiological Medicine, 63, 151-164

[5] Tu, C.C., Li, C.S., Liu, C.M. and Liu, C.C. (2011) Comparative Use of Biomedicine and Chinese Medicine in Taiwan: Using the NHI Research Database. Journal of Alternative and Complementary Medicine, 17, 339-346.

https://doi.org/10.1089/acm.2010.0200

[6] Jong, M.S., Hwang, S.J., Chen, Y.C., Chen, T.J., Chen, F.J. and Chen, F.P. (2010) Prescriptions of Chinese Herbal Medicine for Constipation under the National Health Insurance in Taiwan. Journal of the Chinese Medical Association, 73, 375383. https://doi.org/10.1016/S1726-4901(10)70081-2

[7] Lin, Y.H. and Chiu, J.H. (2011) Use of Chinese Medicine by Women with Breast Cancer: A Nationwide Cross-Sectional Study in Taiwan. Complementary Therapies in Medicine, 19, 137-143. https://doi.org/10.1016/j.ctim.2011.04.001

[8] Navo, M.A., Phan, J. and Vaughan, C. (2004) An Assessment of the Utilization of Complementary and Alternative Medication in Women with Gynecologic or Breast Malignancies. Journal of Clinical Oncology, 22, 671-677. https://doi.org/10.1200/JCO.2004.04.162

[9] Liu, J.P., Yang, H., Xia, Y. and Cardini, F. (2009) Herbal Preparations for Uterine Fibroids. Cochrane Database of Systematic Reviews, 2, Article ID: CD005292. https://doi.org/10.1002/14651858.CD005292.pub2

[10] Murayama, T., Yamaguchi, N., Iwamoto, K. and Eizuru, Y. (2006) Inhibition of Ganciclovir-Resistant Human Cytomegalovirus Replication by Kampo (Japanese 
Herbal Medicine). Antiviral Chemistry \& Chemotherapy, 17, 11-16. https://doi.org/10.1177/095632020601700102

[11] Akçay, N., Bor, M., Karabudak, T., Özdemir, F. and Türkan, İ. (2012) Contribution of Gamma Amino Butyric Acid (GABA) to Salt Stress Responses of Nicotiana sylvestris CMSII Mutant and Wild Type Plants. Journal of Plant Physiology, 169, 452-458. https://doi.org/10.1016/j.jplph.2011.11.006

[12] Brozoski, T., Odintsov, B. and Bauer, C. (2012) Gamma-Aminobutyric Acid and Glutamic Acid Levels in the Auditory Pathway of Rats with Chronic Tinnitus: A Direct Determination Using High Resolution Point-Resolved Proton Magnetic Resonance Spectroscopy (H-MRS). Frontier Systems Neuroscience, 6, 9.

[13] Abo, T., Kawate, T., Itoh, K. and Kumagai, K. (1981) Studies on the Bioperiodicity of the Immune Response. 1. Circadian Rhythms of Human T, B and K Cell Traffic in the Peripheral Blood. Journal of Immunology, 126, 1360-1363.

[14] Yamaguchi, N., Kawada, N., Jia, X.-S., Okamoto, K., Okuzumi, K., Chen, R. and Takahashi, T. (2013) Overall Estimation of Anti-Oxidant Activity by Mammal Macrophage. Open Journal of Rheumatology and Autoimmune Diseases, 4, 13-21. https://doi.org/10.4236/ojra.2014.41002

[15] Kumagai, T. (1978) Studies of Surface Immunoglobulins on Human B Lymphocytes. Physiological Variations of Sig+ Cells in Peripheral Blood. Clinical Experimental Immunology, 33, 441-452.

[16] Landmann, R.M.A., Muller, F.B., Perini, C., Wesp, M., Erne, P. and Buhler, F.R. (1984) Changes of Immunoregulatory Cells Induced by Psychological and Physical Stress: Relationship to Plasma Catecholamines. Clinical Experimental Immunology, 58, 127-135.

[17] Iio, A., Ohguchi, K., Naruyama, H., Tazawa, S., Araki, Y., Ichihara, K., Nozawa, Y. and Ito, M. (2012) Ethanolic Extract of Brazilian Red Propolis ABC A1 Expression and Promote Cholesterol Efflux from THP-1 Macrophage. Phytomedicine, 19, 383 388. https://doi.org/10.1016/j.phymed.2011.10.007

[18] Kitada, Y., Okamoto, K., Takei, T., Jia, X.-F., Chen, R., Yamaguchi, N., Tsubokawa, M., Wu, W.H., Murayama, T. and Kawakita, K. (2013) Hot Spring Hydro Therapy Regulate Peripheral Leukocyte Together with Emotional Hormone and Receptor Positive Lymphocytes According to Each Constitution/Condition. Open Journal of Rheumatology and Autoimmune Diseases, 3, 140-153. https://doi.org/10.4236/ojra.2013.33022

[19] Jerne, N.K. and Nordin, A.A. (1963) Plaque Formation in Agar by Single Antibody Producing Cells. Science, 140, 405-408. https://doi.org/10.1126/science.140.3565.405

[20] Jerne, N.K., Nordin, A.A. and Henry, C. (1963) The Agar Technique for Recognizing Antibody Producing Cells. In: Amons, B. and Kaprowski, H., Eds., Cell-Bound Antibodies, The Wistar Institute Press, Philadelphia, 109-125.

[21] Hamada, M. and Yamaguchi, N. (1988) Effect of Kanpo Medicine, Zyuzentaihotô, on the Immune Reactivity of Tumor-Bearing Mice. Journal of Ethnopharmacology, 24, 311-320. https://doi.org/10.1016/0378-8741(88)90160-2

[22] Shimizu, S., Kitada, H., Yokota, H., Yamakawa, J., Murayama, T., Sugiyama, K., Izumi, H. and Yamaguchi, N. (2002) Activation of the Alternative Complement Pathway by Agaricus blazei Murill. Phytomedicine, 9, 536-545. https://doi.org/10.1078/09447110260573047

[23] Yamaguchi, N., Ueyama, T., Amat, N., Yimit, D., Hoxur, P., Sakamoto, D., Katoh, Y., Watanabe, I. and Su, S.Y. (2015) Bi-Directional Regulation by Chinese Herbal Formulae to Host and Parasite for Multi-Drug Resistant Staphylococcus aureus in 
Humans and Rodents. Open Journal of Immunology, 5, 18-32. https://doi.org/10.4236/oji.2015.51003

[24] Jyumonji, N. and Fujii, Y. (1993) A New Assay for Delayed-Type Hypersensitivity in Vitro Detection Macrophage Migration by Boyden Chamber. Journal of Kanazawa Medical University, 18, 198-203.

[25] Wan, W., Li, A.I., Izumi, H., Kawada, N., Arai, M., Takada, A., Taru, A., Hashimoto, H. and Yamaguchi, N. (2002) Effect of Acupuncture on Leukocyte and Lymphocyte Sub-Population in Human Peripheral Blood Qualitative Discussion. The Journal of Japanese Association of Physical Medicine, Balneology and Climatology, 65, 207-211.

[26] Wang, X.X., Katoh, S. and Liu, B.X. (1998) Effect of Physical Exercise on Leukocyte and Lymphocyte Subpopulations in Human Peripheral Blood. Cytometry Research, 8, 53-61.

[27] Yamaguchi, N., Shimizu S. and Izumi H. (2004) Hydrotherapy Can Modulate Peripheral Leukocytes: An Approach to Alternative Medicine. In: Cooper, E.L. and Yamaguchi, N., Eds., Complementary and Alternative Approaches to Biomedicine, Kluwer Academic/Plenum Publishers, New York, 239-251.

https://doi.org/10.1007/978-1-4757-4820-8 18

[28] Murayama, T., Yamaguchi, N., Matsuno, H. and Eizuru, Y. (2004) In Vitro Anti-Cytomegalovirus Activity of Kampo (Japanese Herbal) Medicine. Evidence-Based Complementary and Alternative Medicine, 1, 285-289.

[29] Abe, S., Yamaguchi, N., Tansho, S. and Yamaguchi, H. (2005) Preventive Effects of Juzen-taiho-to on Infectious Disease. In: Yamada, H. and Saiki, I., Eds., Juzentaiho-to (Shi-Quan-Da-Bu-Tang) Scientific Evaluation and Clinical Applications, CRC Press, Boca Raton.

\section{Abbreviations}

CAM: Complementary and alternative medicine, beside the western medicine, there are many traditional medicine and/or health promoting menu all over the world.

CD: Cluster of differentiation. Each lymphocyte has name that expressed CD number, for example CD2, CD4, etc.

$f$-ESH: Fermented Coffee that had been depredated to micro fragment by Lactobacillus.

FCM: Flow Cytometry.

G-rich type: An individual that exhibit over $60 \%$ of granulocyte in peripheral blood, finding many in young gentleman.

L-rich type: An individual that exhibit over $40 \%$ of lymphocyte in peripheral blood, finding lot in ladies and senile. 
Submit or recommend next manuscript to SCIRP and we will provide best service for you:

Accepting pre-submission inquiries through Email, Facebook, LinkedIn, Twitter, etc. A wide selection of journals (inclusive of 9 subjects, more than 200 journals)

Providing 24-hour high-quality service

User-friendly online submission system

Fair and swift peer-review system

Efficient typesetting and proofreading procedure

Display of the result of downloads and visits, as well as the number of cited articles Maximum dissemination of your research work

Submit your manuscript at: http://papersubmission.scirp.org/

Or contact ojra@scirp.org 